\title{
La constitucionalidad de la mediación y su proyección al ámbito penal: referencia a la legislación de México, España y Panamá
}

\author{
The constitutionality of mediation and its projection to the \\ criminal sphere: reference to the law of Mexico, Spain and \\ Panama
}

\author{
Arnulfo Sánchez García ${ }^{1}$ \\ Yulisán Fernández Silva ${ }^{2}$
}

\begin{abstract}
RESUMO
La mediación, desde la óptica de los derechos humanos, ha tenido un crecimiento exponencial dentro de los diversos modelos de justicia que impulsan su instrumentación. Sin embargo, su posicionamiento no ha sido en todos los casos, desde la jerarquización normativa que propugna el reconocimiento constitucional de los mecanismos alternativas de solución de controversias como requisito para su articulación. Ello se debe, a que algunos ordenamientos jurídicos promueven la introducción de la mediación, como activo inseparable de la facultad prestacional de acceso a la justicia concedida a los ciudadanos; o también, como una interpretación extensiva del derecho a la tutela judicial efectiva. En el presente trabajo se analizan los criterios interpretativos que rigen sobre la mediación como herramienta de garantía de derechos dentro de la órbita de los preceptos constitucionales; y su proyección hacia el ámbito penal, tomando como referencia las legislaciones de México, España y Panamá.
\end{abstract}

PALAVRAS-CHAVE:

Mediación, rango constitucional, acceso a la justicia, tutela judicial.

\begin{abstract}
Mediation, from the perspective of human rights, has had exponential growth within the various models of justice that promote its implementation. However, its position has not been in all cases, from the normative hierarchy that advocates the constitutional recognition of Alternative Conflict Resolution Methods as a requirement for their articulation. This is due to the fact that some legal systems promote the introduction of mediation, as an inseparable asset of the provisional power of access to justice granted to citizens; or also, as an extensive interpretation of the right to effective judicial protection. The article evaluates the interpretative criteria that govern mediation as a tool to guarantee rights within the scope of constitutional precepts; and its projection towards the penal sphere, taking as reference the laws of Mexico, Spain and Panama.

\footnotetext{
${ }^{1}$ Doctor en la Universidad Rey Juan Carlos. Profesor titular de derecho de la Universidad Autónoma de Nuevo León. Abogado. Investigador del Centro de Investigación de tecnología Jurídica y Criminología de la facultad de Derecho y Criminología de la misma Universidad. Investigador Nacional Nivel I Conacyt (SNI-I). Secretario General de la Asociación Internacional de Doctores en Métodos Alternos de Solución de Conflictos ASID/MASC. correo arnulfosanchezgarcia@hotmail.com y arnulfo.sanchezgrc@uanl.edu.mx

${ }^{2}$ Doctorando en Métodos Alternos de Solución de Conflictos y Becario Conacyt en la Universidad Autónoma de Nuevo León, México. Máster en Criminología por la Universidad de la Habana, Cuba. Profesor de Derecho Penal y Cultura de Paz por la misma Universidad. Correo fedezyulisan@ gmail.com.
} 


\section{INTRODUCCIÓN}

La consolidación en el ámbito internacional de la mediación y los otros mecanismos alternativos de solución de controversias (en lo adelante MASC) es un hecho, a partir de la promulgación de instrumentos jurídicos supranacionales, que, sin abordar aún toda la gama de los conflictos susceptibles de autocomposición, sí tienen una incidencia en la orientación del derecho interno en busca de una mayor participación de los ciudadanos en la autogestión de los conflictos, así como, el reforzamiento de los derechos y garantías fundamentales.

En ese sentido son notables los esfuerzos realizados por los organismos internacionales para generar transformaciones en las ordenamientos nacionales, uno de especial relevancia es la aprobación de la enmienda a la Ley Modelo sobre Conciliación Comercial Internacional, mediante resolución 73/199 de 20 de diciembre de 2018, mediante la cual se le ha modernizado adecuándola a las nuevas tendencias globales, sufriendo una modificación en su denominación, quedando como Ley Modelo Sobre Mediación Comercial Internacional y Acuerdos de Transacción Internacionales Resultantes de la Mediación, la cual no solamente sustituye el termino conciliación por el de mediación, sino que contemplan una propuesta normativa sobre la ejecución transfronteriza de los acuerdos resultantes de los procesos de mediación internacionales ${ }^{3}$.

Todo anterior se sustenta en que la incorporación de los MASC ha coadyuvado a restituir el sentido humanista de las funciones de procuración y administración de justicia, diversificándose además las vías de acceso a la justicia ${ }^{4}$, generando con esto un mayor intercambio gobierno-ciudadanía ${ }^{5}$. En ese sentido, la mediación ha acaparado una mayor atención dentro del conglomerado de vías autocompositivas no adversariales, debido a que

\footnotetext{
${ }^{3}$ Resolución de las Naciones Unidas A/res/73/199. Disponible en https://undocs.org/es/A/RES/73/199. Fecha de acceso 14 de Abril. 2020.

${ }^{4}$ Sobre el particular, Pascual Ortuño sostiene que efectivamente la mediación es una herramienta que apunta al mejoramiento de la justicia, por tratarse de una herramienta que permite a los operadores jurídicos acceder a un esquema consensuado, donde las negociaciones previas han fracasado. Ortuño Muñoz, P. LA MEDIACIÓN COMO MEDIO DE SOLUCIÓN DE CONFLICTOS. En: Pillado González, E. y Fariña Rivera, F. Mediación familiar: Una nueva visión de la gestión y resolución de conflictos familiares desde la justicia terapeútica (pp.1535). Valencia: Tirant lo blanch. 2015.

5 Gorjón Gómez, G. d. MEDIACIÓN: EL PARADIGMA JURÍDICO DEL SIGLO XXI. En P. A. Cabello Tijerina, La multidisciplinariedad de la mediación y sus ámbitos de aplicación (pp.72-85). México D.F: Tirant lo blanch. 2015.
} 
reconoce y reivindica a las partes como las verdaderas titulares del conflicto, actuando el mediador como facilitador del diálogo mendiante a aplicación de técnicas y herramientas de negociación ${ }^{6}$, empero, dejando la autogestión a sus protagonistas. De ahí que la mediación se considere un mecanismo rigurosamente voluntario ${ }^{7}$, existiendo una mayor proclividad a la suscripción de acuerdos y su cumplimiento voluntario.

Sin embargo, aunque ya es percibida la eficacia de estos dispositivos no adversariales, aún está pendiente un mayor respaldo gubernamental a partir de políticas públicas, apoyo técnico, y un presupuesto indispensable ${ }^{8}$. Lo cual debe estar aparejado de esquemas de formación de la ciudadanía en materia de autoresponsabilidad en la gestión del conflicto y cultura de paz.

Así, la incorporación progresiva de las vías pacíficas de solución de controversias como un complemento viable y cotidiano dentro de los ordenamientos jurídicos, que permita poner en práctica los resortes pacificadores del conflicto y llegar a nuevos escenarios más allá de la justicia tradicional, debe ser una tarea que el Estado debe procurar de manera sostenida, incrementando paulatinamente los foros de acceso, pero también depurando los mecanismos jurídicos que concedan eficacia a los MASC y sus productos resolutivos.

Lo planteado hasta aquí invita a la reflexión, en consonancia con ello, líneas abajo se presenta un análisis sobre la incorporación de la mediación en diversos modelos de justicia y su resonancia en la esfera penal, visualizando las normativas vigentes en México, España y Panamá. El tópico mencionado adquiere especial relevancia a partir del debate — en diversas corrientes doctrinales - sobre la positivación de los MASC dentro del ordenamiento constitucional como requisito de instrumentación; o desde una segunda tesis, que postula su legitimación y disponibilidad, con la promulgación de una ley orgánica, o inclusive, una regulación indicativa del Poder Judicial.

\footnotetext{
6 Sánchez García, A. Esquemas de mediación y Arbitraje. Ciudad de México: Tirant lo Blanch. 2019.

7 Cornelio Landero, E. LOS MECANISMOS ALTERNATIVOS DE SOLUCIÓN DE CONTROVERSIAS COMO DERECHO HUMANO. BARATARIA. Revista Castellano-Manchega de Ciencias sociales (núm. 17), pp. 81-95. 2014.

8 Ríos Vega, L. E., y Días Rendón, S. LA MEDIACIÓN COMO ELEMENTO CENTRAL DE LA JUSTICIA RESTAURATIVA EN MATERIA DE DERECHOS HUMANOS. En: P. A. Cabello Tijerina, La Multidisciplinariedad de la mediación y sus ambitos de aplicación (pp. 154-172). México D.F: Tirant lo Blanch. 2015.
} 


\section{LA MEDIACIÓN EN EL RANGO CONSTITUCIONAL. CRITERIOS INTERPRETATIVOS}

Las directrices en materia de solución de controversias, en especial la mediación, han sido incorporadas en los esquemas jurídicos de los Estados, desde diferentes enfoques interpretativos. Ello responde, a la proyección de diferentes aportaciones científicas en cuanto al posicionamiento de la mediación y los MASC en la esfera jurídica.

A su vez, la Constitución constituye el punto de referencia obligada para académicos y los operadores jurídicos, considerando que la relevancia de sus preceptos permite hacer valer los derechos humanos, al otorgarle virtualidad por vía de su regulación en ese rango, pero con las herramientas de subjetivación operadas mediante la actuación procesal ante los órganos jurisdiccionales ${ }^{9}$.

Es decir, la ley fundamental ha dejado de ser fuente de fuentes, para convertirse en muchas ocasiones en norma aplicable por los operadores del derecho, por lo que, ante los órganos jurisdiccionales nace el vínculo de dichas normas y el derecho procesal, que deriva en un servicio de administración de justicia habilitado para este fin.

En razón de lo anterior, algunas legislaciones ya han incorporado dentro del catálogo de los derechos fundamentales las herramientas de solución de controversias; mientras otros ordenamientos hacen uso de ellos como extensión y amplitud del reconocimiento del acceso a la justicia por los ciudadanos aparejado al proceso judicial tradicional. Ello obedece, a que el reconocimiento internacional de los MASC y su eficacia para afianzar la cultura de paz ha creado el espacio idóneo para la introducción de la justicia alternativa, tomando en cuenta sus efectos positivos hacia la forma de gestionar los conflictos, tanto en escenarios del derecho privado como en el público.

\footnotetext{
${ }^{9}$ Ver Cutié Mustelier, J., y Méndez López, J. Derechos y Garantías Judiciales. En C. d. autores, Los Derechos Constitucionales (p. 352-359). la Habana. Unijuris. 2012.
} 
Por otro lado, cierto es que la mediación y los MASC en general, contribuyen al estado de felicidad ${ }^{10}$ y satisfacción personal en los individuos sin que ello implique vulnerar valores y principios constitucionales; aspecto que ha determinado que su inserción se realice a través de normas ad hoc en algunos países. De ahí que, en opinión de algunos tratadistas no resulta indispensable que los mecanismos alternativos contengan rango constitucional, ni conformen objeto de estudio del Derecho Constitucional, para su instrumentalización ${ }^{11}$.

Esta línea de pensamiento sostiene, que el Derecho Constitucional debe erigirse como un Derecho de Mínimos, porque le es jurídicamente imposible preverlo todo. Esto significa, que solo debe contemplar los contenidos mínimos del proceso de creación de las normas jurídicas, que cimientan la estructura y funcionamiento del Estado, así como sus instituciones más importantes ${ }^{12}$. Por lo que, desde esa postura doctrinal, ningún texto constitucional escrito deberá abarcar todas las normas fundamentales, considerando que resultará necesario incorporar normas jurídicas que materialicen los pilares constitucionales.

En contraposición a lo anterior, otra línea científica considera que la justicia alternativa representa un postulado fundamental dentro de los modelos de derecho a nivel global. En consecuencia, cualquier esquema constitucional debe prever el uso de estas herramientas pacíficas, sin que ello implique para lograr su operatividad y eficacia, la demora de una reforma legislativa que salvaguarde su uso como derecho fundamental. Es decir, estos esquemas de control de constitucionalidad deberán refrendar el uso de MASC como un pilar representativo de $\operatorname{paz}^{13}$

Desde esta misma percepción, algunos tratadistas consideran que la mediación y los MASC, más allá de constituirse propiamente como derechos, representan garantías primarias de obligación de prestación, al ser herramientas que el Estado debe poner a disposición de los

\footnotetext{
${ }^{10}$ Gorjón Gómez, F. J. Mediación su valor intangible y efectos operativos: Una visión integradora de los métodos alternos de solución de conflictos. Ciudad de México: Tirant lo Blanch. 2017.

${ }^{11}$ Nuñez Torres, M. LA CONSTITUCIONALIDAD DE LOS MASC EN EL ESTADO DE NUEVO LEÓN. En Steele Garza, J.(Coord.), mediación y arbitraje. Leyes comentadas y conrconrdadas del estado de Nuevo León (p. 207-218). México D.F: Porrúa. 2009.

${ }^{12}$ Robles Rosales, W. EL DERECHO CONSTITUCIONAL Y LA CIENCIA POLÍTICA: DE LA CONFUSIÓN AL ESCLARECIMIENTO. 2014. 10 de Noviembre. 2019. Disponible en https://www.coursehero.com/file/29068797/WalterRoblesRosalesdoc/.

13 Leal Espinoza, J. L. MARCO NORMATIVO Y EFECTO DE LOS CONTROLES DE LA CONSTITUCIONALIDAD: LA MEDIACIÓN COMO SOLUCION COMPLEMENTARIA A LA ADMINISTRACIÓN DE JUSTICIA. En P. A. Cabello Tijerina, La multidisciplinariedad de la mediación y sus ambitos de aplicación. (pp. 135-150). México D.F, Mexico: tirant lo blanch. 2015.
} 
ciudadanos, refrendándose en la propia norma constitucional, para resguardar los derechos humanos a la libertad personal y a vivir en paz. Constituyen, además, garantías secundarias tendentes a asegurar la reparación del daño, a partir de los derechos subjetivos que hubieren sido violentados por conductas ilícitas ${ }^{14}$.

En ese orden de ideas, Martiñón Cano considera que el hecho de que el acceso a la justicia implique el reconocimiento de un derecho subjetivo y la obligación del Estado en garantizar el ejercicio legítimo de ese derecho, conlleva a que el Estado deberá proporcionar los medios necesarios para que los ciudadanos puedan solucionar sus controversias de manera eficaz $^{15}$.

De ahí que los MASC, por su naturaleza, sean reconocidos como instrumentos efectivos de solución de conflictos, que asegura el derecho de acceso a la justicia a partir de la utilización de esquemas alternativos a los tradicionales; ${ }^{16}$ escenario que apertura una especie de plurivía ${ }^{17}$, ampliando el espectro de herramientas jurídicas para resolver controversias.

Cierto es que la eficacia de las vías no contenciosas es un hecho, por ello deben estructurarse un grupo de normas que permitan garantizar la instrumentación y ejecutoriedad de los acuerdos logrados por la mediación y los MASC, pues esto legitima su implementación y todos los esfuerzos materiales que el Estado debe aportar para su realización.

Por lo que, a fin de lograr una justicia más garantista, el derecho de acceso a la justicia constituye el escenario ideal, para la incorporación de las herramientas pacíficas de solución de conflictos, a partir de una nueva perspectiva de proyección de este derecho, cambiando el paradigma de justicia hacia la socialización de conflicto ${ }^{18}$.

\footnotetext{
14 Tapia Vega, R. LA SOLUCIÓN ALTERNATIVA DE CONFLICTOS PENALES EN MÉXICO COMO MECANISMO DE GARANTÍA DE DERECHOS HUMANOS. En J. Cabrera Dircio, D. A. Montero Zendejas, O. Huertas Díaz. Derechos humanos y justicia alternativa (p. 199-214). Ciudad de México: fontamara. 2018. 15 Martiñon Cano, G. LA JUSTICIA RESTAURATIVA EN MATERIAL PENAL COMO REALIZACIÓN DEL PRINCIPIO DEL ACCESO A LA JUSTICIA. En F. J. Gorjón Gomez; M. Cano; A. Sanchez García; J. Zaragoza Huerta, Mediación Penal y Justicia Restaurativa. (p. 37-60). México D.F:Tirant lo Blanch.2014.

16 Cappelletti, M., \& Garth, B. El acceso a la justicia., 2019. Disponible en http://revistas.juridicas.unam.mx/index.php/derecho-comparado/article/view/2143/2400. Recuperado el 6 de Marzo de 2020.

${ }^{17}$ Martiñon Cano, Op.cit., p. 43.

18 Islas Colín, A. LA MEDIACIÓN Y LOS MECANISMOS ALTERNATIVOS DE SOLUCIÓN DE CONTROVERSIAS COMO DERECHO HUMANO. En F. J. Gorjón Gómez, y R. Chavéz de los Ríos, manual de mediación familiar, civil, familiar y justicia restaurativa. (p. 133-142). México D.F: Tirant lo Blanch. 2018.
} 


\section{PROYECCIÓN NORMATIVA DE LA MEDIACIÓN PENAL DESDE EL DERECHO COMPARADO TOMANDO COMO REFERENCIA LAS LEGISLACIONES DE MÉXICO, ESPAÑA Y PANAMÁ}

El asentamiento definitivo de los MASC en el sistema jurídico mexicano tendría su máxima expresión en la reforma de los artículos 16, 17, 18, 19, 20, 21, 22 de la Constitución Política de los Estados Unidos Mexicanos, publicada en el Diario Oficial de la Federación del 18 de junio del 2008. En la modificación se perfila un nuevo sistema de justicia penal, a través de la incorporación del modelo acusatorio que demanda un reforzamiento de los derechos fundamentales desde una visión inédita de la actuación del Ministerio Público, en función de impulsar a los ciudadanos a participar activamente en la administración y el cauce de su conflicto $^{19}$.

El modelo acusatorio abre paso a la oralidad y la presencia de la judicatura en todas las audiencias, incluyéndose en el artículo 17 de la Ley fundamental a los mecanismos alternativos de solución de conflictos como un redimensionamiento del derecho de acceso a la justicia; escenario que determina un esquema de justicia penal notoriamente más garantista porque se constituye como una nueva gama de derechos tanto para el imputado, pero también para la víctima u ofendido.

Las leyes orgánicas mantendrían en su estructura la nueva visión del ordenamiento constitucional, promulgándose el Código Nacional de Procedimientos Penales en marzo del 2014 y reformulándose el 17 de junio del 2016, con la incorporación de los pilares del sistema acusatorio. Se incorpora en el propio texto, en los artículos 184 y $185^{20}$, las fórmulas pacificas de solución de controversias ${ }^{21}$.

\footnotetext{
${ }^{19}$ En ese sentido García Ramírez, S. La reforma penal constitucional (2007-2008): ¿Democracia o autoritarismo? México: Porrúa. 2009.

${ }^{20}$ Pérez Daza hace hincapié en que la inclusión de estos mecanismos ayuda a fortalecer las relaciones interpersonales, toda vez que sus sesiones tienen en cuenta en su realización la dignidad de la persona. Pérez Daza, A. Código Nacional de Procedimientos Penales: Teoría y práctica del proceso penal acusatorio. Ciudad de México: Tirant lo Blanch. 2016.

${ }^{21}$ Gorjón Gómez, G. d. LA MEDIACIÓN Y LA CONCILIACIÓN COMO FORMAS DE EXTINCIÓN PENAL. En F. P. Arellano Hernández, \& P. A. Cabello Tijerina. Retos y perpectivas de los masc en México (p. 451- 464). México D.F: Tirant lo Blanch. 2015.
} 
Por su parte, la Ley Nacional de Mecanismos Alternativos de Solución de Controversias en materia penal-LMASCMP_ publicada en fecha 29 de diciembre del 2014, en el Diario Oficial de la Federación, vendría a regular el cauce procesal de los MASC, ya sea en la etapa de investigación o en sede judicial, así como la identificación de sus participantes: deberes y derechos de los intervinientes, forma de solicitar el dispositivo no adversarial y la materia disponible ${ }^{22}$.

Otro aspecto significativo de la legislación penal mexicana es que establece un catálogo de delitos mediables en los que podrán suscribirse acuerdos reparatorios: delitos que se persiguen por querella, delitos culposos, y delitos patrimoniales cometidos sin violencia sobre las personas. Además, la normativa incorpora una limitante para utilización de los dispositivos alternativos, en imputados que con anterioridad hayan suscrito acuerdos sobre los mismos tipos penales dolosos que se le juzga, también en delitos de violencia familiar, así como, para indiciados que hayan incumplido acuerdos reparatorios. ${ }^{23}$

Lo anterior, fundamentado en el artículo 73.XXI.c) de la Carta Magna que reserva al Congreso Federal la potestad de legislar en materia de justicia alternativa penal, determinó la incorporación de un modelo unificado de justicia alternativa penal en México, con un efecto armonizador a nivel nacional, habilitándose una legislación específica con criterios rígidos sobre la instrumentación de los MASC, en el ordenamiento penal ${ }^{24}$.

De lo anterior puede colegirse que en la actualidad mexicana coexisten de manera armónica dos vías de acceso a la justicia, la forma tradicional y las salidas no contenciosas; lo que demuestra que sus postulados no son excluyentes, sino que pueden gravitar dentro del mismo ordenamiento jurídico y aplicarse en mejor beneficio del caso en concreto.

Por su parte en España, la regulación normativa de los MASC no cuenta con un reconocimiento constitucional de manera independiente, sino que se contempla como una interpretación extensiva del derecho a la tutela judicial efectiva teniendo una proyección

\footnotetext{
${ }^{22}$ Adame Rivera, M. G. MARCO NORMATIVO E HISTORICO DE LA MEDIACIÓN Y LOS MASC EN MATERIAL PENAL, CIVIL Y MERCANTIL. En F. J. Gorjón Gómez, y R. Chávez de los Rios. Manual de mediación penal,civil, familiar y justicia restaurativa. Para mediadores, facilitadores e instructores (p. 117-132). Ciudad de México: Tirant lo Blanch. 2018.

${ }^{23}$ Alcántar Mendoza, G. Legislacion Penal Nacional.Ciudad de México:Gallardo Ediciones. 2018.

${ }^{24}$ Sánchez García, A. Esquemas de mediación y arbitraje. Ciudad de México: Tirant lo Blanch. 2019.
} 
importante en los ámbitos civil, mercantil y familiar; a partir de la promulgación de leyes que logran cohesionar el cauce procesal de las vías autocompositivas en la nación de la península ibérica.

En este sentido, hay que entender que el enfoque de la mediación penal desde la perspectiva de la tutela judicial efectiva no implica necesariamente la sustitución o eliminación de la actuación judicial en la administración de justicia, sino que la vía no adversarial constituye un espacio de participación con protagonismo de la ciudadanía en la solución del conflicto, aspecto reflejado en el art. 125 de la Constitución española.

Sin embargo, en el ámbito penal no ha tenido el mismo crecimiento y homogeneidad, la promulgación de normativas dirigidas a introducir los mecanismos alternativos. La disponibilidad de normas jurídicas de vías no adversariales ha tenido una producción indistinta dentro de las Comunidades Autónomas, desde la década de los noventa, materializándose a través de la elaboración de protocolos de mediación, los cuales han sido sometidos a la aprobación del Consejo General de Poder Judicial (CGPJ).

La propuesta presentada, responde a la necesidad de acoger los postulados que la Unión Europea impulsa a los Estados en cuanto a la introducción de modalidades autocompositivas en el área penal. En primer orden, la Decisión Marco del Consejo de la Unión Europea del 15 de marzo del 2001 (2001/220/JAI), aborda lo relativo al estatuto de la víctima en el proceso penal $^{25}$; y con posterioridad, en la Directiva 2012/29/UE del Parlamento Europeo, así como del Consejo con fecha 25 de octubre de 2012 - que sustituye a la anterior-, se establecen normas mínimas sobre los derechos, el apoyo y la protección de las víctimas de delitos ${ }^{26}$.

Los instrumentos recogidos en la normativa europea profundizan en la instauración de un régimen de protección de víctimas con la conformación de un sistema de reparación y atención integral al ofendido.

\footnotetext{
25 Para un análisis sobre el contexto legal comunitario sobre mediación penal véase Freiré Pérez, R. M. EXPERIENCIAS DE MEDIACIÓN PENAL EN EL ÁMBITO DE LA JUSTICIA PENAL PARA ADULTOS. AMPARO NORMATIVO E INSTITUCIONAL. En: Martín Diz, F. La mediación en materia familiar y Derecho Penal, (pp.257-282). Santiago de Compostela: Andavira. 2011.

${ }^{26}$ Ojeda Soler, R. N. (2016). Mediación penal en adultos. Trabajo fin de título máster en acceso a la abogacía. Universidad de Salamanca. Salamanca. España. 2016.
} 
Hay que señalar, que la promulgación de la Ley Orgánica 5/2000, del 12 de enero, sobre responsabilidad penal de los menores constituye el primer referente normativo general promulgado en España, que instaura la mediación dentro del proceso penal, con menores infractores $^{27}$, incluyendo como una causal del sobreseimiento, la aplicación del acuerdo por conciliación y reparación del daño.

De igual modo, la mediación penal de adultos ha ido ganando espacio, puesto que, aún carente de regulación legal, ha conseguido incorporarse al Sistema de Justicia penal, a través de experiencias recabadas de la aplicación de programas piloto, aprobados por el Consejo General de Poder Judicial.

Precisamente el CGPJ coordinó el desarrollo de experiencias piloto sobre mediación penal en las que participaron más de cuarenta juzgados de instrucción y de lo penal a nivel nacional, y cuyos resultados se recogen en el estudio sobre Justicia Restaurativa y Mediación penal: Análisis de una Experiencia (2005-2008) ${ }^{28}$.

La experiencia de los programas de este tipo, sin norma habilitante, que se han venido desarrollando en territorio español desde hace más de dos décadas, institucionalizados por entidades privadas o públicas, han permitido extender los servicios de mediación, y promover su institucionalización ${ }^{29}$.

Los resultados alcanzados sobre mediación impulsaron al CGPJ en el 2016, publicados en guía para la práctica de mediación intrajudicial que armoniza los criterios procedimentales sobre su instrumentalización en las diversas áreas del derecho. En el documento, se hace referencia a los diferentes instrumentos jurídicos nacionales e internacionales que legitiman el

\footnotetext{
${ }^{27}$ Para un exhaustivo estudio sobre los principios informadores de la Ley Orgánica 5/2000, de responsabilidad penal de menores véase Pillado González, E. LA MEDIACIÓN COMO MANIFESTACIÓN DEL PRINCIPIO DE OPORTUNIDAD DE LA LEY DE RESPONSABILIDAD PENAL DE MENORES. En: Pillado González, E. Mediación penal con menores infractores en España y los paises de su entorno, (pp.53-87). Valencia: Tirant lo blanch. 2012.

28 Ortuño Muñoz, P. PANORAMA DE LOS MEDIOS ALTERNATIVOS DE RESOLUCIÓN DE CONTROVERSIAS, Y SU IMPACTO EN LA MODERNIZACIÓN DE LA JUSTICIA. Revista jurídica de Catalunya, Vol. 115(1), p. 33-44. 2016.

${ }^{29}$ Barona Vilar, S. JUSTICIA PENAL CONSENSUADA Y JUSTICIA PENAL RESTAURATIVA, ¿ALTERNATIVA OCOMPLEMENTO DEL PROCESO PENAL? LA MEDIACIÓN PENAL, INSTRUMENTO ESENCIAL DEL NUEVO MODELO. IUS. Revista del Instituto de Ciencias Jurídicas de Puebla A.C, Número (24), p. 76-113, 2009.
} 
uso de mecanismos no contenciosos de solución de $\operatorname{conflictos}^{30}$. En la esfera penal, la recomendación antes señalada del CGPJ tiene como propósito, el respaldo a los jueces para que estos puedan derivar a mediación mediante la promoción de la firma de protocolos en las Comunidades Autónomas.

Como nota distintiva, el documento no proporciona un catálogo de delitos mediables, sino que existe un amplio espectro sobre la materia disponible comprendiendo desde faltas hasta delitos graves; y limitando únicamente su aplicación a delitos sin víctima y los delitos resultantes de la violencia de género.

En resumen, aún sin Ley, la mediación penal en España tiene una gran utilidad derivándose casos desde los Juzgados de Instrucción, Juzgados de Enjuiciamiento, así como en los tribunales y en la ejecución de sentencias.

Por otra parte, la incorporación de las modalidades de solución anticipada en el ordenamiento jurídico de Panamá no ha fluido desde la jerarquización normativa, sino que ha ido instrumentándose en las leyes orgánicas, propiciando su reconocimiento desde su operatividad.

En este sentido, la Constitución de Panamá reconoce la justicia arbitral como un componente inseparable a la administración de justicia. Esto se ve reflejado en el art. 202 del cuerpo legal ${ }^{31}$ :

ARTICULO 202. El Órgano Judicial está constituido por la Corte Suprema de Justicia, los tribunales y los juzgados que la Ley establezca. La administración de justicia también podrá ser ejercida por la jurisdicción arbitral conforme lo determine la Ley. Los tribunales arbitrales podrán conocer y decidir por sí mismos acerca de su propia competencia.

Lo anterior demuestra que existe una intención, a partir de desarrollo de política públicas del Estado panameño, de reconocer otras modalidades de solución de conflictos ajenas al

\footnotetext{
${ }^{30}$ Consejo General del Poder Judicial. Guía para la práctica de la mediación intrajudicial. 2016. Disponible en http// www.poderjudicial.es > stfls > CGPJ > MEDIACIÓN > FICHERO > 20161. Recuperado el 11 de Noviembre de 2019.

${ }^{31}$ ASAMBLEA NACIONAL. TRÁMITE LEGISLATIVO. 2019. Disponible en https://www.asamblea.gob.pa/sites/default/files/2019-07/ACTO-LEGISLATIVO-N1.pdf. Recuperado el 5 de Marzo de 2020.
} 
formato adversarial, que sin dudas resultan relevantes para optimizar la función jurisdiccional y otorgarles a los ciudadanos un espacio más cercano a la satisfacción de sus intereses ${ }^{32}$.

Ello impacta indudablemente en la recuperación del sentimiento de seguridad, al tener un modelo de justicia más comprometido con la ciudadanía, lo que deriva en una mayor confianza en las instituciones que integran el poder judicial.

Ahora bien, como ya se ha podido percibir la mediación no se encuentra incluida dentro de los dispositivos regulatorios que han sido incorporados en la Carta Magna de Panamá, aspecto que no ha resultado óbice para su introducción al ámbito penal.

En ello, cobra especial importancia la proyección del derecho de acceso a la justicia en la legislación panameña, contemplado en los art. 41, 42 y 43 de la Ley Fundamental en cumplimiento del art.25 de la Convención Interamericana de Derechos Humanos ${ }^{33}$.

Sobre este tópico hay que señalar que como otros ordenamientos foráneos — ver Constitución de México - la Ley Fundamental panameña contempla una referencia al derecho prestacional de acceso a la justicia sin que exista una definición; aunque si afloran algunos aspectos que permiten identificarlos.

Los artículos 41, 42 y 43 del cuerpo legal mencionado, proyectan un grupo de garantías a los ciudadanos a través de la protección al quejoso, también a presentar una reclamación, o a requerir del Estado una actuación diligente; convirtiéndose esta garantía en un postulado accesible para todos.

Por tanto, el acceso a un recurso efectivo, sencillo y rápido, mediante el cual los jueces y tribunales tutelen de manera eficaz el ejercicio de los derechos humanos de toda persona que lo solicite, sustanciados de conformidad con las reglas del debido proceso legal, es

\footnotetext{
${ }^{32} \mathrm{Al}$ respecto, Soler Mendizábal explica como diversos dispositivos de la Ley 5 de 8 de julio de 1999 relativos al arbitraje, fueron considerados inconstitucionales por la Corte Suprema de Justicia de Panamá, razón por lo que se decidió elevar el arbitraje a rango constitucional. Soler Mendizábal, R. Procedimientos alternativos de solución de conflictos en la justicia penal acusatoria. Ciudad de Panamá: Barrios \& Barios. 2017.

${ }^{33}$ Vease Constitución Política de la República de Panamá, 2004. Art. 41, 42 y 43. Disponible en http://pdba.georgetown.edu/Parties/Panama/Leyes/constitucion.pdf. Recuperado el 6 de Marzo de 2020.
} 
consecuencia del derecho fundamental a la tutela judicial efectiva, en tanto que asegura la obtención de justicia pronta, completa e imparcial. ${ }^{34}$

El caso de Panamá, hay que destacar que la proyección de salidas alternativas no quedó solo en el marco de la Carta Magna, sino que, en respaldo a esa misma supremacía constitucional, desde el poder ejecutivo se emitieron normas que apoyan a la consolidación de los métodos no tradicionales de solución de controversias. Ello se patentiza con la promulgación el Decreto Ley No. 5 de fecha 8 de Julio de 1999, instrumento legal que además de desarrollar las pautas esenciales que regirán en lo adelante para la instrumentación de la justicia arbitral en el país; introduce las figuras de la mediación y la conciliación como otras vías de gestión de conflictos que también tendrán alcance nacional. ${ }^{35}$

El cuerpo legal dedica el Capítulo II — artículos del 52 al 58 - al proceso de mediación, y tiene como aspectos interesantes, que se reconocen los servicios de mediación tanto en el ámbito público como en el privado, y además se autoriza a que la mediación pueda celebrarse judicialmente o extrajucialmente constando como requisito de procedibilidad, que la suscripción del convenio sea sobre materias susceptibles de transacción, previamente reglamentadas en la legislación ${ }^{36}$.

Y aunque con posterioridad, la necesidad de actualización de normas arbitrales que determinan la derogación Decreto No.5 de 1999, por la Ley No.131 del 31 de diciembre del 2013, quedaron vigentes las figuras de la mediación y la conciliación que tendrían una gran significación en esferas como la penal ${ }^{37}$.

La promulgación de normas sobre mediación también llegó a las instituciones de persecución y administración de justicia, con el objetivo de estructurar el servicio y adiestrar al personal que se encargaría de intervenir como mediadores en centros públicos. En sede del Ministerio Público, se promulgaron normativas como la Resolución No. 50 del 20 de junio del 2013, por la que se crea la Secretaria Nacional de Solución de Conflictos, adscrita la

\footnotetext{
${ }^{34}$ Tribunales Colegiados de Circuito, 2012. Tesis 2002096. II.8o.(I Región) 1 K (10a.). Semanario Judicial de la Federación y su Gaceta. Libro XIII, , Décima Ëpoca(p.2864), Nuevo León, México. 2012.

${ }^{35}$ Decreto Ley No.5. Por el que se establece el Régimen General de Arbitraje, de la Conciliación y de la Mediación. GACETA OFICIAL ÓRGANO DEL ESTADO. Ciudad de Panamá, Panamá. 1999.

${ }^{36}$ Ídem

${ }^{37}$ Soler Mendizábal, R. Procedimientos alternativos de solución de conflictos en la justicia penal acusatoria. Ciudad de Panamá: Barrios \& Barios. 2017.
} 
Procuraduría General de la Nación. También, se promulgan otros acuerdos que autorizan la creación de Centros Alternos de Resolución de Conflictos en el órgano judicial. Resalta entre ellos el Acuerdo No. 294 del 2001, promulgado por la Corte Suprema de Justicia que habilita a los órganos judiciales como como entes auxiliares y facilitadores de la mediación extrajudicial. Este instrumento legal fue suprimido por el Acuerdo 225 del 2003, y posteriormente por los Acuerdos No. 252 del 2006, y No.685 de las 2015 normativas que autorizan la creación de centros de mediación para promover los MASC, así como programas de capacitación para formar mediadores y conciliadores del poder judicial y extender el servicio por todo el país ${ }^{38}$.

Por otra parte, la legislación procesal penal de la nación centroamericana también recibió una modificación significativa, conforme a los postulados del nuevo modelo acusatorio incorporado al Sistema de Justicia Penal, y también de las experiencias recibidas de la aplicación de la mediación y la conciliación reconocidas en el Decreto Ley No.5 de 1999. El resultado se materializa con la promulgación de la Ley No.63, del 28 de agosto del 2008, Código Procesal de la República de Panamá, legislación que incluiría la mediación y la conciliación como figuras no adversariales, con un procedimiento exclusivo.

El nuevo Código Procesal tienen como aspectos destacados, la configuración de salidas alternas a través de la mediación y conciliación, permitiendo a la víctima y al imputado participar colaborativamente en la definición del proceso y definir la reparación del daño, que puede ser de naturaleza económica, o también conllevar al otorgamiento del perdón ${ }^{39}$.

En función de conseguir este propósito, la propia normativa reconoce la importancia de la actuación del Ministerio Público y el Órgano Judicial—artículos 26 y 69 del Código Procesal penal-, identificando entre sus funciones la de procurar resolver el conflicto surgido a través de los MASC, evitando con ello la aplicación de una pena, para contribuir con ello a restaurar la paz, y el orden social vulnerado ${ }^{40}$.

Este designio, también se ve reflejado en el artículo 272 del propio cuerpo normativo, que dispone dentro del objeto de investigación, que la procuración de la resolución del conflicto

\footnotetext{
${ }^{38}$ Soler, 2018, Op.Cit., p. 179.

39 Rodríguez Castro, J. CONCILIACIÓN Y MEDIACIÓN. En M. P. Nación, Código Procesal Penal De La República De Panamá (COMENTADO) (p.216-219). Ciudad de Panamá: IMPRESIONES CARPAL.2018.

${ }^{40}$ Procuraduría General de la Nación. Código Procesal Penal De La República De Panamá (Comentado). Ciudad de Panamá: IMPRESIONES CARPAL. 2018.
} 
es un propósito que debe buscarse dentro del trámite de investigación, si ello resultara posible; interpretándose con esto, que la acción penal solo debe continuar cuando no pueda aplicarse una salida alterna al proceso.

Al mismo tiempo, la derivación a vías alternas deberá cumplir los estándares de la materia disponible, por lo que no será posible aplicarlo ni en todos los casos ni a todas las personas.

Sobre este tópico, la ley procesal define los tipos penales en los que se puede prescindir de la pretensión punitiva, por lo que será este el rango que definirá las materias susceptibles de aplicación de los MASC. El artículo 201 del cuerpo legal, establece un catálogo de delitos mediables el cual podrá revisarse, cuando las partes estén interesadas en acceder al servicio. El catálogo incluye delitos contra la vida y la integridad corporal de carácter culposo; y también otras figuras - que pueden ejecutarse de forma intencional — que atentan contra la propiedad, la familia, el honor, el libre desarrollo de las relaciones sexuales, así como algunas falsedades documentales.

Los aspectos mencionados hasta aquí corroboran que el Sistema de Justicia panameño es uno de los más actualizados en materia de mecanismos alternativos de solución de conflictos en la región, tomando en cuenta que existe un interés desde las instituciones gubernamentales de acercar la justicia a los ciudadanos, y lograr una actuación expedita y efectiva de los órganos jurisdiccionales. Ello aparejado a un intenso programa de capacitación impulsado por el Órgano Judicial, donde, por ejemplo, actualmente se desarrolla el Doctorado en Métodos Alternos de Solución de Conflictos en colaboración con la Universidad Autónoma de Nuevo León, para formar a jueces, magistrados y funcionarios judiciales en general.

Como se ha podido apreciar, la instrumentación y operatividad de la mediación, no ha seguido un único cauce en los diversos modelos de justicia vigentes en la actualidad, cada país ha ajustado a su ordenamiento jurídico estas vías no adversariales, de acuerdo con su estructura social, buscando perfeccionar el servicio de justicia, desde un reforzamiento de los derechos fundamentales y una mayor participación de los principales protagonistas: los ciudadanos. 


\section{CONCLUSIONES}

Como idea conclusiva puede plantearse que la instrumentalización de la mediación puede estar presente, tanto en modelos que prevén su reconocimiento desde la supremacía constitucional; así como, desde una interpretación extensiva del derecho a la tutela judicial efectiva, que realizan los jueces para impulsar programas para la aplicación de estas vías pacíficas de solución de controversias; y también, desde una profundización de derecho de acceso a la justicia con la implementación de normas que pueden emanar del poder ejecutivo.

La vía utilizada no ha sido la misma, sin embargo, desde los diversos modelos de ejercicio, el impacto de la mediación en la transformación de los conflictos y en la generación de una cultura de paz, ha sido tan notable, que los propios gobiernos han ido adaptando sus ordenamientos jurídicos de manera que les permita utilizar este y otros dispositivos no adversariales lo antes posible; sin que ello implique perder de vista la legalidad que debe primar en todo Sistema de Justicia.

De tal suerte que no puede decirse, en sentido estricto, que la mediación y los MASC requieren inexcusablemente ser incorporados al catálogo de derechos fundamentales — aunque definitivamente ese sea el fin deseado - para adquirir virtualidad jurídica; considerando que la justicia alternativa representa un espacio dentro del acceso a la justicia de los ciudadanos que ya es reconocido.

Por ello, resulta frágil la idea de una reformulación total del esquema sustantivo y procesal vigente de un país, así como su consecuente dilación y empleo de recursos, para la inclusión de la mediación y los MASC. El compromiso se enmarca en el perfeccionamiento del modelo vigente, al que puedan integrarse en lo procedimental, nuevas fórmulas inclusivas que viabilicen el acceso a la justicia.

En consecuencia, todavía se necesita informar y concientizar a la ciudadanía, así como a los operadores del Sistema de Justicia, sobre los beneficios que pueden seguirse de la implementación de un modelo más cercano a los ciudadanos y no tanto a la tradición jurídicopenal; lo que representa una vía saludable al mejorar la credibilidad en la administración de la justicia. 


\section{REFERENCIAS}

Adame Rivera, M. G. MARCO NORMATIVO E HISTORICO DE LA MEDIACIÓN Y LOS MASC EN MATERIAL PENAL, CIVIL Y MERCANTIL. En F. J. Gorjón Gómez, y R. Chávez de los Rios. Manual de mediación penal,civil, familiar y justicia restaurativa. Para mediadores, facilitadores e instructores (p. 117-132). Ciudad de México: Tirant lo Blanch. 2018.

Alcántar Mendoza, G. Legislacion Penal Nacional. Ciudad de México:Gallardo Ediciones.2018.

ASAMBLEA NACIONAL. TRÁMITE LEGISLATIVO. 2019.Disponible en https://www.asamblea.gob.pa/sites/default/files/2019-07/ACTO-LEGISLATIVO-N1.pdf. Recuperado el 5 de Marzo de 2020.

Barona Vilar, S. JUSTICIA PENAL CONSENSUADA Y JUSTICIA PENAL RESTAURATIVA, ¿ALTERNATIVA OCOMPLEMENTO DEL PROCESO PENAL? LA MEDIACIÓN PENAL, INSTRUMENTO ESENCIAL DEL NUEVO MODELO. IUS. Revista del Instituto de Ciencias Jurídicas de Puebla A.C, Número (24), p. 76-113, 2009.

Cappelletti, M., \& Garth, B. El acceso a la justicia., 2019. Disponible en http://revistas.juridicas.unam.mx/index.php/derecho-comparado/article/view/2143/2400.

Recuperado el 6 de Marzo de 2020.

Consejo General del Poder Judicial. Guía para la práctica de la mediación intrajudicial. 2016. Disponible en http// www.poderjudicial.es > stfls > CGPJ > MEDIACIÓN > FICHERO > 20161. Recuperado el 11 de Noviembre de 2019.

Constitución Política de la República de Panamá, 2004.Disponible en http://pdba.georgetown.edu/Parties/Panama/Leyes/constitucion.pdf. Recuperado el 6 de Marzo de 2020 .

Cornelio Landero, E. LOS MECANISMOS ALTERNATIVOS DE SOLUCIÓN DE CONTROVERSIAS COMO DERECHO HUMANO. BARATARIA. Revista CastellanoManchega de Ciencias sociales(núm. 17), pp. 81-95. 2014.

Cutié Mustelier, J., y Méndez López, J. Derechos y Garantías Judiciales. En C. d. autores, Los Derechos Constitucionales (p. 352-359). la Habana. Unijuris. 2012.

Decreto Ley No.5. Por el que se establece el Régimen General de Arbitraje, de la Conciliación y de la Mediación. GACETA OFICIAL ÓRGANO DEL ESTADO. Ciudad de Panamá, Panamá. 1999.

García Ramírez, S. La reforma penal constitucional (2007-2008): ¿Democracia o autoritarismo. México: Porrúa. 2009 
Gorjón Gómez, G. d. LA MEDIACIÓN Y LA CONCILIACIÓN COMO FORMAS DE EXTINCIÓN PENAL. En F. P. Arellano Hernández, \& P. A. Cabello Tijerina. Retos y perpectivas de los MASC en México (p. 451- 464). México D.F: Tirant lo Blanch. 2015.

Gorjón Gómez, G. d. MEDIACIÓN: EL PARADIGMA JURÍDICO DEL SIGLO XXI. En P. A. Cabello Tijerina ,La multidisciplinariedad de la mediación y sus ámbitos de aplicación(pp.72-85). México D.F: Tirant lo blanch.2015.

Islas Colín, A. LA MEDIACIÓN Y LOS MECANISMOS ALTERNATIVOS DE SOLUCIÓN DE CONTROVERSIAS COMO DERECHO HUMANO. En F. J. Gorjón Gómez, y R. Chavéz de los Ríos, manual de mediación familiar, civil, familiar y justicia restaurativa. (p. 133-142). México D.F: tirant lo blanch. 2018.

Leal Espinoza, J. L. MARCO NORMATIVO Y EFECTO DE LOS CONTROLES DE LA CONSTITUCIONALIDAD: LA MEDIACIÓN COMO SOLUCION COMPLEMENTARIA A LA ADMINISTRACIÓN DE JUSTICIA. En P. A. Cabello Tijerina, La multidisciplinariedad de la mediación y sus ambitos de aplicación. (pp. 135-150). México D.F, Mexico: tirant lo blanch. 2015.

Martiñon Cano, G. La JUSTICIA RESTAURATIVA EN MATERIAL PENAL COMO REALIZACIÓN DEL PRINCIPIO DEL ACCESO A LA JUSTICIA. En F. J. Gorjón Gomez; M. Cano; A. Sanchez García; J. Zaragoza Huerta, Mediación Penal y Justicia Restaurativa. (p. 37-60). México D.F:Tirant lo Blanch.2014

Nuñez Torres, M. LA CONSTITUCIONALIDAD DE LOS MASC EN EL ESTADO DE NUEVO LEÓN. En Steele Garza, J.(Coord.), mediación y arbitraje. Leyes comentadas y conrconrdadas del estado de Nuevo León (p.207-218). México D.F: Porrúa. 2009.

Ojeda Soler, R. N. (2016). Mediación penal en adultos. Trabajo fin de título máster en acceso a la abogacía. Universidad de Salamanca. Salamanca. España. 2016.

Ortuño Muñoz, P. LA MEDIACIÓN COMO MEDIO DE SOLUCIÓN DE CONFLICTOS. En: Pillado González, E. y Fariña Rivera, F. Mediación familiar: Una nueva visión de la gestión y resolución de conflictos familiares desde la justicia terapeútica (pp.15-35). Valencia: Tirant lo blanch. 2015.

Ortuño Muñoz, P. PANORAMA DE LOS MEDIOS ALTERNATIVOS DE RESOLUCIÓN DE CONTROVERSIAS, Y SU IMPACTO EN LA MODERNIZACIÓN DE LA JUSTICIA.Revista jurídica de Catalunya, Vol. 115(1), p. 33-44. 2016.

Pérez Daza, A. Código Nacional de Procedimientos Penales: Teoría y práctica del proceso penal acusatorio. Ciudad de México: Tirant lo Blanch. 2016.

Pillado González, E. LA MEDIACIÓN COMO MANIFESTACIÓN DEL PRINCIPIO DE OPORTUNIDAD DE LA LEY DE RESPONSABILIDAD PENAL DE MENORES. En: Pillado González, E. Mediación penal con menores infractores en España y los paises de su entorno, (pp.53-87). Valencia: Tirant lo blanch. 2012. 
Procuraduría General de la Nación. Código Procesal Penal De La República De Panamá (COMENTADO). Ciudad de Panamá: IMPRESIONES CARPAL. 2018.

Ríos Vega, L. E., y Días Rendón, S. LA MEDIACIÓN COMO ELEMENTO CENTRAL DE LA JUSTICIA RESTAURATIVA EN MATERIA DE DERECHOS HUMANOS. En P. A. Cabello Tijerina, La Multidisciplinariedad de la mediación y sus ambitos de aplicación (pp. 154-172). México d.f: tirant lo blanch. 2015.

Robles Rosales, W. EL DERECHO CONSTITUCIONAL Y LA CIENCIA POLÍTICA: DE LA CONFUSIÓN AL ESCLARECIMIENTO. 2014.Recuperado el 10 de Noviembre de 2019,Disponible en:

https://www.coursehero.com/file/29068797/WalterRoblesRosalesdoc/.

Rodríguez Castro, J. CONCILIACIÓN Y MEDIACIÓN. En M. P. Nación, Código Procesal Penal De La República De Panamá (Comentado) (p.216-219). Ciudad de Panamá: IMPRESIONES CARPAL.2018.

Sánchez García, A. Esquemas de mediación y arbitraje. Ciudad de México: tirant lo blanch. 2019

Soler Mendizábal, R. Procedimientostos alternos de solucion de conflictos en la Justicia Penal Acusatoria. Ciudad de Panamá: BARRIOS BARRIOS. 2017.

Tapia Vega, R. LA SOLUCIÓN ALTERNATIVA DE CONFLICTOS PENALES EN MÉXICO COMO MECANISMO DE GARANTÍA DE DERECHOS HUMANOS. En J. Cabrera Dircio, D. A. Montero Zendejas, O. Huertas Díaz. Derechos humanos y justicia alternativa (p. 199-214). Ciudad de México: fontamara. 2018.

Tribunales Colegiados de Circuito, 2012. Tesis 2002096. II.8o.(I Región) 1 K (10a.). Semanario Judicial de la Federación y su Gaceta. Libro XIII, , Décima Ëpoca(p.2864), Nuevo León, México.2012.

Data de Submissão: 01/08/2020

Data de Aceite: 12/08/2020 